J. Dairy Sci. 100:849-849

https://doi.org/10.3168/jds.2017-100-1-0849

(c) American Dairy Science Association ${ }^{\circledR}, 2017$.

\title{
Corrigendum to "Effects of dietary nitrogen levels and carbohydrate sources on apparent ruminal synthesis of some $B$ vitamins in dairy cows" (J. Dairy Sci. 99:2730-2739)
}

\author{
V. Beaudet, R. Gervais, B. Graulet, P. Nozière, M. Doreau, A. Fanchone, D. S. Castagnino, and C. L. Girard
}

In this paper, we used erroneous values for the molecular weight of thiamin and vitamers of vitamin $\mathrm{B}_{6}$. This error had limited effects on the overall results or statistical significance; however, several values reported in text and in tables are incorrect. The error affected statements in the Thiamin (page 2735) and Vitamin $\mathrm{B}_{6}$ (page 2737) subsections of the Results and Discussion, as well as values of thiamin and vitamin $\mathrm{B}_{6}$ reported in Table 1 (page 2732), Table 2 (page 2735), and Table 3 (page 2735), and correlation coefficients for ARS of vitamin $B_{6}$ in Table 4 (page 2736).

A revised version of this paper containing the corrections noted above has been published as supplementary data (see file below).

The authors regret the errors.

Supplementary Data: Corrected Article

View File

\section{REFERENCES}

Beaudet, V., R. Gervais, B. Graulet, P. Nozière, M. Doreau, A. Fanchone, D. S. Castagnino, and C. L. Girard. 2016. Effects of dietary nitrogen levels and carbohydrate sources on apparent ruminal synthesis of some B vitamins in dairy cows. J. Dairy Sci. 99(4):2730-2739. 10.3168/ jds.2015-10521. 